\title{
Испытания на устойчивость К воздействию HIRF-полей
}

\author{
А. Петровичев ${ }^{1}$
}

УДК 608.4 | ВАК 05.11.01

\begin{abstract}
В лаборатории ЭМС АО «ТЕСТПРИБОР» проводятся испытания бортового оборудования (БО) расчетно-экспериментальным методом на стойкость K HIRF-полям в соответствии со стандартом КT-160. В настоящий момент проходит аттестацию реверберационная камера. По ее завершении лаборатория получит возможность проводить весь спектр проверок на стойкость K HIRF-полям, соответствующий требованиям KT-160, обеспечивая результат, близкий к натурным испытаниям.
\end{abstract}

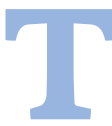

ема испытаний бортового оборудования на устойчивость К воздействию электромагнитных помех, наведенных излучаемым электромагнитным полем, хорошо освещена, но есть одна неочевидная проблема, с которой могут столкнуться как испытательные лаборатории, так и изготовители БО на стадии испытаний.

Проведение испытаний на соответствие требованиям основополагающего стандарта для военной и гражданской авиации (КТ-160) на первый взгляд не вызывает трудностей: методики есть и давно отработаны, существует и подходящее техническое оснащение.

При этом есть отдельная категория наведенных электромагнитных полей, известная под аббревиатурой HIRFHigh-intensity Radiated Field (высокоинтенсивные излучаемые поля). В стандарте КT-160 HIRF представлены для каждой категории испытуемого БО, их значения размещены в таблицах уровней воздействия второй колонкой. В качестве примера приведем конкретные значения: от 150 до 1400 В / м в диапазоне от 400 до 1000 МГц и от 500 до 7000 В / м в диапазоне выше 1000 Мгц.

Стандартное оснащение лаборатории позволяет получить значения напряженности электромагнитного поля до 200 В / м на частотах до 1000 МГц и до 1000 В / м в гигагерцовом диапазоне. Повышение уровня напряженности поля в первом приближении является не самой просто решаемой задачей, однако на практике уже применяются методы проведения подобных испытаний.

\section{МЕТОДЫ ИСПЫТАНИЙ}

Самым простым может показаться метод прямого воздействия поля соответствующей напряженности на испытуемое БО. Достаточно лишь взять подходящую антенну и усилитель мощности и подать воздействие...

Однако так просто это звучит лишь в теории. При попытке практической реализации такого метода

АО «ТЕСТПРИБОР», ИЛ ЭМС, инженер-испытатель. возникают проблемы, связанные с технической стороной вопроса. Подходящих антенн для таких испытаний может просто не оказаться, усилителей, которые могли бы дать соответствующее усиление, либо опять же не существует, либо они являются слишком дорогим удовольствием.

В качестве варианта можно рассматривать магнетроны, но каждый магнетрон создается под конкретное значение частоты, поэтому при испытаниях во всем необходимом диапазоне частот потребуется несколько устройств, которые нужно будет переключать в течение проверки. И добавим к этому требования безопасности к испытательной площадке.

Есть и альтернативные методы, не требующие такой сложной технической подготовки

Первый - расчетно-экспериментальный метод, основанный на измерении ослабления поля корпусом БО с последующим облучением внутренних блоков и компонентов без корпуса. Уровень воздействующего поля определяется с учетом ослабления, которое дает корпус. Это - технически легко осуществимый метод, нашедший широкое практическое применение. Однако он не может быть использован в следующих случаях:

- если БО изготовлено в единственном экземпляре (опытный образец) в герметичном корпусе без возможности его вскрыть;

- если отсутствует идентичный макет испытуемого БО;

- если внутренние размеры корпуса БО не позволяют разместить в нем антенну для измерения экранирования корпуса.

В этих случаях прибегают к использованию реверберационных камер.

\section{ЧТО ТАКОЕ РЕВЕРБЕРАЦИЯ}

Реверберация - это процесс многократного сложения переотраженной от поверхности волны. Речь может идти 
о волнах любого рода: довольно часто, например, этот термин применяется в области акустики и звукозаписи. Но так как мы говорим об ЭМС, то применяем понятие реверберации к электромагнитным волнам.

Именно принцип многократного сложения волны лежит в основе работы реверберационной камеры. Многократно переотраженные волны входят в резонанс, что приводит к значительному росту величины напряженности электромагнитного поля в рабочем объеме камеры. И значения до 7000 в/м перестают быть недосягаемыми!

\section{KAK УСTPOEHA KAMEPA}

Реверберационная камера представляет собой экранированное помещение, не обшитые поглощающим материалом внутренние стенки которого обеспечивают отражение волн. Для лучшего отражения стенки и пол камеры делают металлическими. Другой важной особенностью камеры является наличие так называемого тюнера или "мешалки» - поворотного механизма с железными пластинами. От его ориентации зависят фаза и амплитуда переотраженных волн и, как следствие, процесс резонанса в рабочем объеме.

Камера представляет собой резонатор с высокой добротностью, что позволяет создать поле с высокой напряженностью в рабочем объеме при подводе сравнительно небольшой мощности. То есть реверберационная камера позволяет создать HIRF-поля как в низкочастотном (до 1 ГГц), так и в высокочастотном (от 1 ГГц) диапазонах. Это позволяет исключить из состава оборудования дорогостоящий усилитель мощности. Но есть важный момент, связанный с размером камеры,- нижняя граница диапазона частот напрямую зависит от размера рабочей области.

Реверберационные камеры чаще всего применяются для испытаний на устойчивость БО к воздействию электромагнитного поля. Другими вариантами применения могут быть измерение эффективности экранирования и измерение эмиссии помех. При этом следует помнить о том, что реверберационная камера не может в полной мере заменить безэховую, в частности, если речь идет об измерении помехоэмиссии.

\section{РЕЗУЛЬТАТЫ ИЗМЕРЕНИЙ}

Проиллюстрируем работу реверберационной камеры результатами измерений. Замеры проводились в камере, собранной АО «ТЕСТПРИБОР».

Параметры камеры:

- общие габариты, мм: 2770 ×1550×1650;

- размеры рабочей зоны, мм: $700 \times 700 \times 700$;

- общий эффективный диапазон частот, гГц: 0,23-40;

- коэффициент экранирования, не менее: - 120 дБ (230-1000 МГц);

- 100 дБ (1-10 ГГц);

- 90 дБ (10-18 ГГц);

- 80 дБ (18-40 ГГц)

Схема рабочего места представлена на рис. 1.

В ходе измерений определялась напряженность электромагнитного поля в рабочем объеме реверберационной камеры в зависимости от угла поворота тюнера. Полученная зависимость суказанием точек измерений представлена на рис. 2.

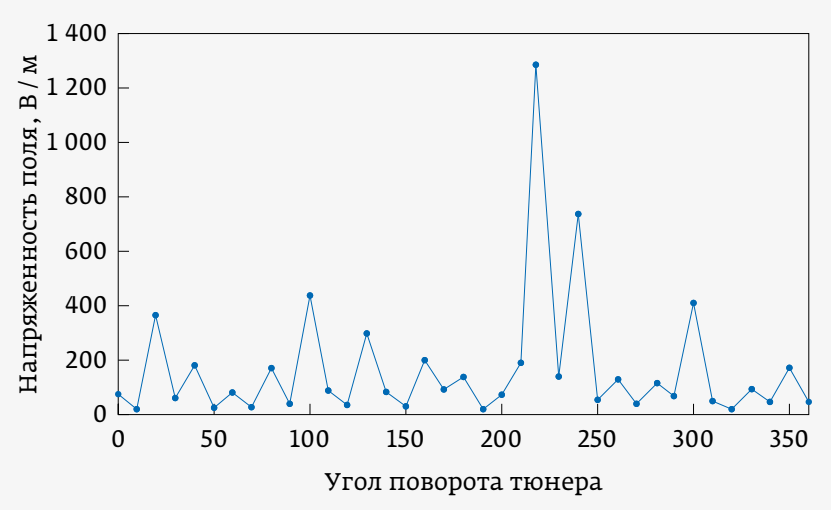

Рис. 2. Зависимость напряженности электромагнитного поля от угла поворота тюнера 
Измерения проводились на частоте 230 МГц с применением стандартного оснащения испытательной лаборатории ЭМС АО «ТЕСТПРИБОР». Как видно из полученной зависимости, при величине угла поворота $218^{\circ}$ напряженность электромагнитного поля равна 1287 В / м. При повороте тюнера на 240 наблюдается побочный пик напряженности, равный 742 В / м.

Другими словами, собранная камера позволяет создать в рабочем объеме поле большой напряженности при использовании стандартного оборудования лаборатории и без мощного усилителя.

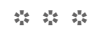

Можно сделать вывод, что проведение испытаний на стойкость оборудования к HIRF-полям является технически сложно реализуемой, но, тем не менее, выполнимой задачей. Метод прямых испытаний имеет альтернативы, одна из которых, расчетно-экспериментальный метод, с одной стороны, заметно проще и дешевле реализуема, но, с другойне обеспечивает полностью достоверных результатов.

Метод с использованием реверберационной камеры имеет очевидный недостаток - стоимость оборудования. Однако на него не распространяются ограничения, справедливые для расчетно-экспериментального метода. Использование реверберационной камеры снимает с испытательной площадки требования по безопасности, о которых упоминалось в начале статьи применительно к прямой проверке изделия. И, наконец, получаемые таким методом результаты максимально близки к результатам натурных испытаний.

\section{КНИГИ ИЗДАТЕЛЬСТВА «ТЕХНОСФЕРА»}

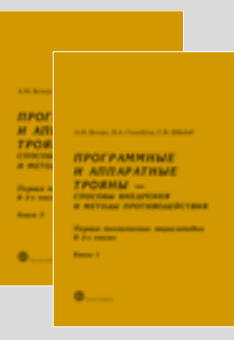

Цена за две книги 2400 руб.

\section{ПРОГРАММНЫЕ И АППАРАТНЫЕ} ТРОЯНЫ - СПОСОБЫ ВНЕДРЕНИЯ И МЕТОДЫ ПРОТИВОДЕЙСТВИЯ. ПЕРВАЯ ТЕХНИЧЕСКАЯ ЭНЦИКЛОПЕДИЯ

\author{
В 2-х книгах
}

\author{
Белоус А. И., Солодуха В. А., Шведов С. В. \\ Под общей редакцией Белоуса А. И.
}

В двухтомнике исследован феномен программных и аппаратных троянов, которые фактически являются технологической платформой современного и перспективного кибероружия. В первой вводной главе показано, что развитие всех "обычных" и "новейших" видов вооружений дошло до такой стадии, что их использование на практике будет равносильно самоубийству начавшей войну стороны. Осознание этого факта привело к развитию информационно-технического оружия (кибероружия и нейрооружия). В последующих главах детально исследованы концепции, методы и примеры реализации этого вида оружия. Рассмотрены основные виды программных троянов, вирусов и шпионских программ, показан эволюционный путь развития аппаратных троянов от «ящиков» и «коробочек» до микросхем.

Книга ориентирована на специалистов по информационной безопасности, а также будет полезна всем интересующимся данной темой. 

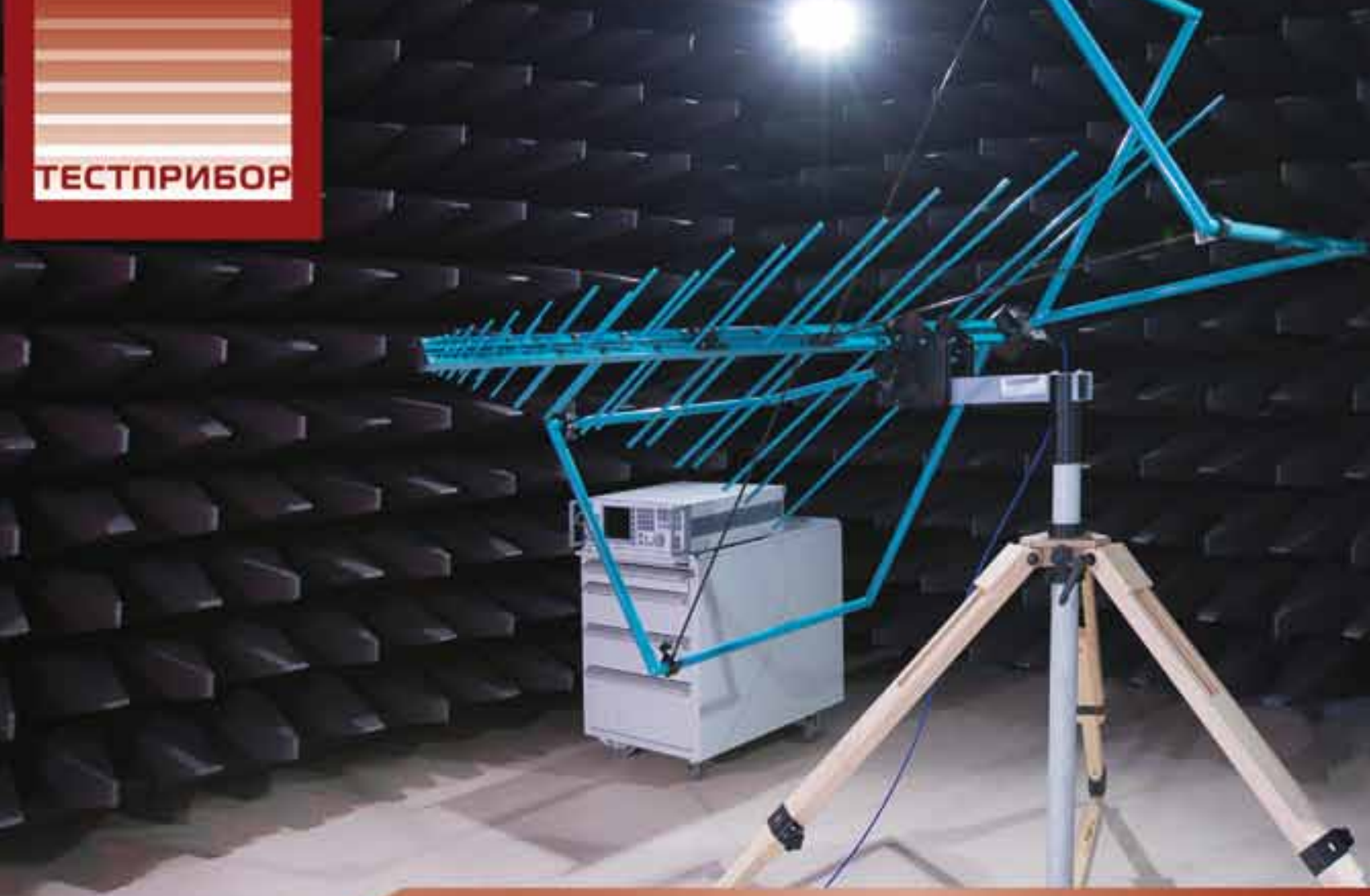

\section{ИСПЫТАНИЯ}

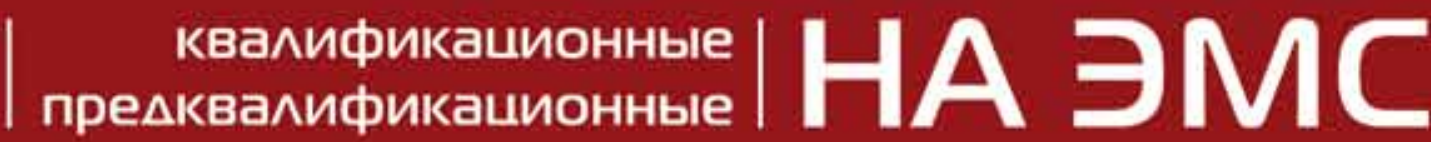

АККРЕДИТОВАННАЯ ИСПЫТАТЕЛЬНАЯ ЛАБОРАТОРИЯ АО «ТЕСТПРИБОР» ПРЕДЛАГАЕТ ПРОВЕДЕНИЕ ИСПЫТАНИЙ:

- На устойчивость к переходным процессам, провалам, прерываниям и изменениям напряжения в системе электропитания.

- На восприимчивость к кондуктивным помехам.

- На устойчивость к воздействию электростатических разрядов.

- На устойчивость к воздействию переходных процессов вызванных молниевым разрядом.

- На устойчивость к воздействию постоянного и переменного магнитного поля.
- Измерение коэффициента экранирования, безэховости и валидация измерительных площадок.

- Измерение уровня кондуктивных помех.

- На устойчивость к воздействию электромагнитных полей различной интенсивности до $40 \mathrm{TTL}$.

- Измерение уровня электромагнитных помех (помехоэмиссия).

- Разработка методики испытаний в соответствии с требованиями ГОСТов и технических заданий. 